\title{
Factors Associated with Under-Five Mortality: A Comparison between Empowered Action Group (EAG) and Non-EAG States of India
}

\author{
Sarvesh Kumar1*, Damodar Sahu², Nishanka Chauhan ${ }^{3}$ \\ ${ }^{1}$ USMPMHS, Guru Gobind Singh Indraprastha University, New Delhi, India \\ ${ }^{2}$ National Institute of Medical Statistics, ICMR, New Delhi, India \\ ${ }^{3}$ State Institute of Health and Family Welfare, Jaipur, India \\ Email: ${ }^{\star}$ awasthi.sarvesh@gmail.com
}

How to cite this paper: Kumar, S., Sahu, D. and Chauhan, N. (2021) Factors Associated with Under-Five Mortality: A Comparison between Empowered Action Group (EAG) and Non-EAG States of India. Health, 13, 1190-1205.

https://doi.org/10.4236/health.2021.1311088

Received: August 17, 2021

Accepted: November 8, 2021

Published: November 11, 2021

Copyright $\odot 2021$ by author(s) and Scientific Research Publishing Inc. This work is licensed under the Creative Commons Attribution International License (CC BY 4.0).

http://creativecommons.org/licenses/by/4.0/

\begin{abstract}
Background: In India under-five mortality (U5MR) has declined by $71 \%$ from 126 to 37 deaths per 1000 live births between 1990 and 2018. The Empowered Action Group (EAG) states accounts for $74 \%$ of the under-five deaths as compared to $26 \%$ among Non-EAG states. Method: National Family Health Survey round fourth (NFHS-4), 2015-16 was used for this study. A life table method and Cox Proportional Hazard (PH) model was used to examine the various factors associated with U5MR in EAG and Non-EAG states of India. Result: Overall, it was observed that U5MR is much higher in EAG compared to Non-EAG states. Absolute difference varies according to background characteristics. The highest difference was among mothers who had never breastfed (316 vs 150 U5MR per 1000 live births in EAG \& Non-EAG states respectively). Factors-total children ever born to mother, household members, children never breastfed and size of the baby were found to be statistically significantly associated with under-five mortality after controlling for other factors in both EAG and Non-EAG states. Hazard of U5MR was two and half-times higher among birth order $4+(\mathrm{AHR}=2.5,95 \% \mathrm{CI}=1.8-3.3)$ compared to birth order $\leq 2$ after controlling for other factors in EAG states. The risk of under-five mortality was found three times higher among mother having up to primary or no education $(\mathrm{AHR}=2.9,95 \% \mathrm{CI}=1.4-5.9)$ compared to mother having higher education in non-EAG states. Conclusion: The study revealed that both groups of states need health program interventions focused on high risk mothers, TT immunization and promoting basic health services and breastfeeding practices for the reduction U5MR.
\end{abstract}




\section{Keywords}

Cox PH, EAG, Non-EAG, NFHS, U5MR

\section{Introduction}

The under-five mortality rate (U5MR) is used as an indicator of overall well-being and health status of children in a country. In 2018, approximately, 5.3 million children of under-five years of age died globally, out of which 0.88 million (16.5\%) were from India. Globally, the U5MR has declined by $59 \%$ from 93 deaths per 1000 live births in 1990 to 39 in 2018, with an annual rate of reduction of $3.1 \%$. In India, there was $71 \%$ decline from 126 deaths per 1000 live births in 1990 to 37 in 2018 [1]. India's rapid reduction in U5MR can be attributed to the ambitious National Rural Health Mission (NRHM) launched in April 2005 by Government of India, wherein the Child Health Program (CHP) comprehensively integrated interventions to improve child health and address factors contributing to infant and under-five mortality. The major components of CHP included establishing newborn care facilities and Facility Based Integrated Management of Neonatal and Childhood Illnesses (F-IMNCI); Navjaat Shishu Suraksha Karyakram; Integrated Management of Neonatal and Childhood Illnesses (IMNCI) and Pre Service IMNCI; home-based care of newborns, universal immunization, early detection and appropriate management of Acute Respiratory Infections (ARI), diarrhea and other infections along with other supplementation and school health programs [2].

Overall India has achieved substantial reduction, but within India, inter and intra-regional variations exists, further complicated by differences between the urban and rural areas. If we compare U5MR between different states of India, the highest U5MR are observed in Uttar Pradesh (78); Madhya Pradesh (65); Chhattisgarh (64); Bihar (58); Assam (56); Jharkhand (54); Rajasthan (51); Uttarakhand (47) and Orissa (48) whereas low U5MR are observed in States/UTs as Kerala (7), Puducherry (16), Goa (13), Andaman \& Nicobar Islands (13) and Lakshadweep (23). They have already achieved the target of Sustainable Development Goal (SDG) for U5MR for 2030 [3] [4].

In order to achieve national health goal, the Ministry of Health and Family Welfare, Government of India, established Empowered Action Group (EAG) of states in 2001 for special focus by monitoring and facilitating the attainment of MDG goals in the poor performing states-Bihar, Chhattisgarh, Jharkhand, Madhya Pradesh, Odisha, Rajasthan, Uttar Pradesh, Uttarakhand and Assam [5]. The EAG states constitute $45 \%$ of the total population of India and contribute $74 \%$ of the under-five deaths as compared to $26 \%$ among Non-EAG States [6]. In order to achieve SDG goals for U5MR in the year 2030 i.e. 25 per 1000 live births, the child survival program needs to be focused on EAG states [7].

Several studies have been carried out on determinants of under-five mortality 
separately for each state/region of India, the present study aimed to examine the factors associated with under-five mortality in EAG and Non-EAG states of India.

\section{Data and Methodology}

\subsection{Data}

India's Demographic Health Survey (DHS) i.e. the National Family Health Survey round fourth (NFHS-4), 2015-16 was used for this study. NFHS-4 collected information on fertility, family planning, infant and child morbidity and mortality, maternal and reproductive health, nutritional status of women and children, and the quality of health services at national and state levels. In NFHS-4, all eligible women aged 15 - 49 years were asked to provide information on complete birth history, which included sex, month and year of birth, and survival status for each live birth [8]. The death information of a child was recorded in days for children who died in the first month of life; in months for children who died after the first month but before completion of their second birthday, and in years for children who had died after second birthday. The present study was restricted to all live births that occurred in the preceding five years of the survey and collected information on antenatal, breastfeeding and post-natal care for analysis of under-five mortality.

\subsection{Study Variables}

\subsubsection{Dependent Variable}

Dependent variable is defined as under-five mortality; the probability of a child born in a specific year or period dying before reaching the age of five years, if subject to age-specific mortality rates of that period, expressed per 1000 live births. It was expressed as binary outcome variable i.e., 1 for death and 0 for alive.

\subsubsection{Independent Variables}

The model by Moseley \& Chen on systematic conceptual framework was used in the selection of explanatory/independent variables in this study. It proposes a set of proximate determinants that directly influences the risk of child mortality. It also proposes that all other socio-economic factors must operate through this set of proximate determinants [9]. We have considered four categories, i.e., demographic, socio-economic, environmental, and health related variables. Demographic variables included were mother's age at first delivery, total number of children ever born, birth order, and sex of child. Socio-economic variables included were mother's education level, household size, wealth index, place of residence, religion and caste. Environment factors were type of toilet facility, type of cooking fuel used. Health factors were maternal tetanus toxoid (TT) immunization, place of delivery, type of delivery, antenatal care (ANC), post-natal care (PNC), breast feeding, and size of the baby at birth. We define following measures as independent variables: 
Wealth index: The level of economic status of a woman was computed as wealth index based on scores on ownership of consumer goods and household characteristics, such as availability of basic facilities like clean drinking water. It then uses this information to classify all households into wealth index.

Sanitation facility: Household having either a flush or pit latrine whether private or shared, were regarded to have 'improved' sanitation as opposed to those without any facility (unimproved). Cooking fuel: The households using liquefied petroleum gas (LPG), electricity, kerosene and biogas were considered as users of low polluting fuels (clean fuel). Those using charcoal, firewood and coal were regarded as users of high polluting fuels (unsafe).

The operational definitions of these variables are given in Table 1.

\subsection{Methodology}

We have used life table method and cox proportional hazard model for the estimation of under-five mortality and to examine factors associated with under-five mortality. The details of methods are given below:

\section{Life table method:}

A life table method is used for estimation of U5MR. For each subject, there is a defined point event, often called failure, occurring after a length of time called the failure time. Failure can occur only once in any subject. This method (usually known as survival analysis) was a significant improvement over the approach of using gross death rates, because it incorporated the actual rates of death observed at various time points following diagnosis or commencement of treatment. Also, this method does not require subjects to enter the study simultaneously and can make use of the data from subjects who have dropped out of the study or are lost to follow-up. The most important aspect of the life table method is the incorporation in the survival analysis of the duration of the time taken to reach the outcome event. So we have constructed life table to estimate probability of death at age 59 months i.e., before reaching fifth birthday by background characteristics of mother and child.

\section{Cox Proportional Hazard model}

A nonparametric survival model for the survival analysis was first introduced by Cox (1978). This model was proposed for the statistical analysis of factors affecting under-five deaths of children. A survival curve is a statistical graph to show the survival experience of children. The advantage of using cox proportional hazard model is censoring of under-five deaths by either survival beyond the total time observed (beyond 60 months) or deaths (before 60 months) of the children. This analysis was performed for independent variables among EAG and Non-EAG states. This study has been designed to identify the effect of those associated factors which were found related to under-five mortality. The hazard function at the time point $\mathrm{t}$ (here) denoted by $\mathrm{h}(\mathrm{t})$

$$
h(t)=h_{0}(t) \exp \left(\beta_{1} x_{1}+\beta_{2} x_{2}+\beta_{3} x_{3}+\beta_{4} x_{4} \ldots+\beta_{i} x_{i}\right),
$$

where, $i=1,2,3,4 \ldots n$. 
Table 1. Definition and categories of independent variables. (a) Demographic variables Definitions/categories; (b) Socio-economic variables; (c) Environmental variables; (d) Health-related variables.

(a)

\begin{tabular}{ccc}
\hline 1 & $\begin{array}{c}\text { Mother's age at the } \\
\text { time of first delivery } \\
\text { Total no of } \\
\text { children ever born }\end{array}$ & $\begin{array}{c}\text { Age group in years } \\
(\leq 15,16-20,21-25,>25)\end{array}$ \\
3 & Birth order & $\begin{array}{c}\text { Total no. of births by the mother in her } \\
\text { reproductive age group }(\leq 2,3-4,>4) \\
\text { The birth order of the child in family } \\
\text { (first, second/third, } \geq \text { fourth) }\end{array}$ \\
4 & Sex of child & Male, Female \\
\hline
\end{tabular}

(b)

\begin{tabular}{ccc}
\hline 1 & Mother's education level & $\begin{array}{c}\text { Mother's level of education } \\
\text { (no education, primary, secondary, higher) }\end{array}$ \\
2 & Family size & Number of members in each household $(\leq 5,>5)$ \\
3 & Wealth index & Wealth status of household \\
4 & Place of residence & Area of the residence (urban, rural) \\
5 & Religion & Religion of respondent (Hindu, Muslim, other) \\
\hline
\end{tabular}

(c)

\begin{tabular}{|c|c|c|}
\hline 1 & Access of Sanitation facilities & $\begin{array}{l}\text { Household access of sanitation } \\
\text { (improved, unimproved) }\end{array}$ \\
\hline 2 & Type of cooking fuel & Use of cooking fuel (clean fuel, solid fuel) \\
\hline & & (d) \\
\hline 1 & Maternal TT immunization & $\begin{array}{c}\text { Tetanus toxoid injection status of mother } \\
\text { during pregnancy (yes/no) }\end{array}$ \\
\hline 2 & Place of delivery & Place of delivery for birth (public, private, home) \\
\hline 3 & Type of delivery & Type of delivery (Caesarian, normal) \\
\hline 4 & Antenatal care & $\begin{array}{l}\text { Attended any no. of ANC visits by the mother } \\
\qquad(\text { yes, no) }\end{array}$ \\
\hline 5 & Postnatal care & $\begin{array}{l}\text { Attended any no. of PNC visits by the mother } \\
\text { (yes, no) }\end{array}$ \\
\hline 6 & Breast feeding & Breast feeding to the child born (yes, no) \\
\hline 7 & Size of baby at birth & Size of the baby born (average, small, large) \\
\hline
\end{tabular}

Variable $t$ denotes the duration (time) of the studied variable, $h(t)$ is the hazard rate at which an event occurs, $h_{0}(t)$ is the baseline hazard function that varies only with $\mathrm{t}$ and for which no specific function is assumed, $\mathrm{x}$ is a vector of independent variables and $\beta$ is a vector of regression parameters.

If $\beta>1$ it means that the covariate has the effect of raising the hazard rate (i.e. 
the covariate is a risk factor), if $\beta<1$ then the covariate is a protective factor, and if $\beta=1$ then it is neutral and exerts no effect. Where $X_{i}$ are explanatory variables, $\beta i$ are regression coefficients and $h_{0}(t)$ is a baseline hazard. It is assumed that the explanatory variables influence the hazard by the same degree at each time point (hence the term "proportional hazards").

\section{Statistical Analysis}

A life table technique used to compute the probability of a child dying before completing five years. The univariate and multivariate survival cox proportional hazard models were used to examine the effects of the explanatory variables on under-five mortality. We have fitted model separately for EAG and Non EAG groups of Indian states. Cox regression is used to analyze time to event data i.e. the response is the time an individual takes to present the outcome variable (Under-five deaths). In this study, children that were still alive at 5 years of age are assigned the total length of time of the follow-up, and are treated as censored, meaning that until the time of the end of the follow-up they are alive. The level of statistical significance was set at $5 \%$. All data analyses were conducted using STATA version 16.

\section{Ethical Considerations}

This study is based on publicly available dataset with no identifiable information on the survey participants. Therefore, no ethics review is required for this work.

\section{Result}

Out of total 190,797 reported live births during past five years preceding the survey 112,481 were from EAG states and 78,316 were from Non-EAG states in India. Overall, there were 5696 under-five deaths, of which 4070 (3.62\%) deaths were in EAG states and 1626 (2.08\%) deaths in Non-EAG states respectively. The weighted U5MR in five years preceding the survey for EAG states is 42 (95\% CI: 41 - 44) per 1000 live births compared with 26 (95 \% CI: 24 - 28) per 1000 live births in Non-EAG states which is $38 \%$ lower.

Table 2 presents the distribution of live births, under-five deaths, and probability of U5MR (5q0) and absolute difference and percent difference of U5MR by background characteristics demographic, socio-economic, and environmental and health related variables for EAG and Non-EAG states. The U5MR (5q0) for the five-year period preceding the survey were computed separately for all proximate variables for both EAG and Non-EAG states of India using life table method. The difference in under-five mortality is measured in terms of absolute and percentage. The estimated U5MRs for the five-year period preceding the survey are much higher in EAG states compared with Non-EAG states for all the proximate variables under study. All the determinants of under-five mortality were observed in terms of absolute \% decline in Non-EAG states to EAG states. It was observed that highest absolute difference (167 under-five deaths per 1000 
Table 2. Distribution of number and percent of live births, number of under-five deaths, U5MR, absolute difference by background characteristics in EAG and Non EAG states of India (2015-16).

\begin{tabular}{|c|c|c|c|c|c|c|c|c|c|}
\hline \multirow{2}{*}{$\begin{array}{l}\text { Background } \\
\text { characteristic }\end{array}$} & \multicolumn{4}{|c|}{ EAG states } & \multicolumn{4}{|c|}{ Non EAG states } & \multirow{2}{*}{$\begin{array}{l}\text { Absolute and \% } \\
\text { difference in } \\
\text { U5MR (5q0) } \\
\text { EAG to } \\
\text { Non EAG states }\end{array}$} \\
\hline & $\begin{array}{l}\text { Live } \\
\text { births }\end{array}$ & $\begin{array}{c}\text { Live } \\
\text { birth } \\
(\%)\end{array}$ & $\begin{array}{l}\text { Under } \\
\text { five } \\
\text { deaths }\end{array}$ & $\begin{array}{c}\text { U5MR } \\
(5 q 0)\end{array}$ & $\begin{array}{l}\text { Live } \\
\text { births }\end{array}$ & $\begin{array}{c}\text { Live } \\
\text { birth } \\
(\%)\end{array}$ & $\begin{array}{l}\text { Under } \\
\text { five } \\
\text { deaths }\end{array}$ & $\begin{array}{l}\text { U5MR } \\
(5 q 0)\end{array}$ & \\
\hline \multicolumn{10}{|c|}{ Mother's age at the time of first delivery } \\
\hline$\leq 15$ & 3249 & 2.9 & 147 & 50.5 & 2124 & 2.7 & 60 & 32.5 & $18.0(35.6)$ \\
\hline $16-20$ & 54,868 & 48.8 & 2079 & 44.0 & 30,648 & 39.1 & 636 & 25.2 & $18.8(42.7)$ \\
\hline $21-25$ & 44,474 & 39.5 & 1489 & 39.2 & 32,247 & 41.2 & 667 & 26.3 & $12.9(32.9)$ \\
\hline$>25$ & 9890 & 8.8 & 355 & 40.7 & 13,297 & 17.0 & 263 & 23.8 & $16.9(41.5)$ \\
\hline \multicolumn{10}{|c|}{ Total no of children ever born } \\
\hline$\leq 2$ & 67,793 & 60.3 & 2075 & 34.7 & 56,478 & 72.1 & 980 & 21.5 & $13.2(38.0)$ \\
\hline $3-4$ & 32,316 & 28.7 & 1224 & 44.7 & 17,345 & 22.1 & 458 & 31.7 & $13.0(29.1)$ \\
\hline$>4$ & 12,372 & 11.0 & 771 & 71.1 & 4493 & 5.7 & 188 & 51.5 & $19.6(27.6)$ \\
\hline \multicolumn{10}{|c|}{ Birth order } \\
\hline First & 33,491 & 29.8 & 1170 & 39.3 & 28,312 & 36.2 & 503 & 23.7 & $15.6(39.7)$ \\
\hline Second/third & 55,127 & 49.0 & 1604 & 34.2 & 40,382 & 51.6 & 754 & 22.0 & $12.2(35.7)$ \\
\hline$\geq$ Fourth & 23,863 & 21.2 & 1296 & 62.1 & 9622 & 12.3 & 369 & 47.5 & $14.6(23.5)$ \\
\hline \multicolumn{10}{|c|}{ Sex of child } \\
\hline Male & 61,669 & 54.8 & 2203 & 41.0 & 41,776 & 53.3 & 888 & 26.5 & $14.5(35.4)$ \\
\hline Female & 50,812 & 45.2 & 1867 & 43.4 & 36,540 & 46.7 & 738 & 24.4 & $19.0(43.8)$ \\
\hline \multicolumn{10}{|c|}{ Mother's educational level } \\
\hline No education & 41,971 & 37.3 & 1924 & 53.6 & 13,134 & 16.8 & 403 & 39.1 & $14.5(27.1)$ \\
\hline Primary & 16,906 & 15.0 & 661 & 45.3 & 9790 & 12.5 & 271 & 31.3 & $14.0(30.9)$ \\
\hline Secondary & 43,946 & 39.1 & 1294 & 33.6 & 44,901 & 57.3 & 834 & 23.3 & $10.3(30.7)$ \\
\hline Higher & 9658 & 8.6 & 191 & 22.5 & 10,491 & 13.4 & 118 & 12.7 & $9.8(43.6)$ \\
\hline \multicolumn{10}{|c|}{ Household members (Family size) } \\
\hline$\leq 5$ & 47,417 & 42.2 & 2331 & 56.6 & 38,967 & 49.8 & 1033 & 32.3 & $24.3(42.9)$ \\
\hline$>5$ & 65,064 & 57.8 & 1739 & 30.8 & 39,349 & 50.2 & 593 & 18.4 & $12.4(40.3)$ \\
\hline \multicolumn{10}{|c|}{ Wealth Index } \\
\hline Poor/poorer & 66,871 & 59.5 & 2829 & 49.9 & 23,592 & 30.1 & 651 & 36.4 & $13.5(27.1)$ \\
\hline Middle & 19,053 & 16.9 & 630 & 37.9 & 19,316 & 24.7 & 440 & 28.6 & $9.3(24.5)$ \\
\hline Rich/richest & 26,557 & 23.6 & 611 & 25.6 & 35,408 & 45.2 & 535 & 17.2 & $8.4(32.8)$ \\
\hline
\end{tabular}




\begin{tabular}{|c|c|c|c|c|c|c|c|c|c|}
\hline \multicolumn{10}{|c|}{ Place of residence } \\
\hline Urban & 22,779 & 20.3 & 647 & 31.9 & 25,035 & 32.0 & 432 & 20.9 & $11.0(34.5)$ \\
\hline Rural & 89,702 & 79.7 & 3423 & 44.7 & 53,281 & 68.0 & 1194 & 27.9 & $16.8(37.6)$ \\
\hline \multicolumn{10}{|c|}{ Religion } \\
\hline Hindu & 92,739 & 82.4 & 3364 & 42.2 & 45,524 & 58.1 & 848 & 23.5 & $18.7(44.3)$ \\
\hline Muslim & 16,940 & 15.1 & 614 & 41.8 & 12,360 & 15.8 & 302 & 28.9 & $12.9(30.9)$ \\
\hline Other & 2802 & 2.5 & 92 & 38.0 & 20,432 & 26.1 & 476 & 28.1 & $9.9(26.1)$ \\
\hline \multicolumn{10}{|c|}{ Access of Sanitation facility } \\
\hline Improved access & 42,614 & 37.9 & 1210 & 32.2 & 53,210 & 67.9 & 1006 & 22.5 & $9.7(30.1)$ \\
\hline Unimproved access & 69,867 & 62.1 & 2860 & 48.2 & 25,106 & 32.1 & 620 & 32.5 & $15.7(32.6)$ \\
\hline \multicolumn{10}{|c|}{ Type of cooking Fuel } \\
\hline Clean fuel & 23,682 & 21.1 & 632 & 29.9 & 33,673 & 43.0 & 552 & 20.7 & $9.2(30.8)$ \\
\hline Solid fuel & 88,799 & 78.9 & 3438 & 45.4 & 44,643 & 57.0 & 1074 & 29.5 & $15.9(35.0)$ \\
\hline \multicolumn{10}{|c|}{ Maternal TT immunization } \\
\hline No & 9165 & 8.1 & 565 & 70.2 & 9059 & 11.6 & 264 & 36.7 & $33.5(47.7)$ \\
\hline Yes & 103,316 & 91.9 & 3505 & 39.5 & 69,257 & 88.4 & 1362 & 24.1 & $15.4(39.0)$ \\
\hline \multicolumn{10}{|c|}{ Place of delivery } \\
\hline Home & 28,529 & 25.4 & 1290 & 52.7 & 13,623 & 17.4 & 397 & 35.2 & $17.5(33.2)$ \\
\hline Public & 63,021 & 56.0 & 1988 & 37.2 & 42,594 & 54.4 & 855 & 25.4 & $11.8(31.7)$ \\
\hline Private & 20,931 & 18.6 & 792 & 41.5 & 22,099 & 28.2 & 374 & 20.1 & $21.4(51.6)$ \\
\hline \multicolumn{10}{|c|}{ Type of delivery } \\
\hline Normal & 100,387 & 89.2 & 3653 & 42.5 & 60,672 & 77.5 & 1314 & 27.1 & $15.4(36.2)$ \\
\hline Caesarian & 12,094 & 10.8 & 417 & 37.8 & 17,644 & 22.5 & 312 & 20.4 & $17.4(46.0)$ \\
\hline \multicolumn{10}{|c|}{ Antenatal care } \\
\hline No & 24,437 & 21.7 & 1187 & 56.9 & 10,958 & 14.0 & 316 & 35.7 & $21.2(37.3)$ \\
\hline Yes & 88,044 & 78.3 & 2883 & 56.9 & 67,358 & 86.0 & 1310 & 23.9 & $33.0(58.0)$ \\
\hline \multicolumn{10}{|c|}{ Postnatal care } \\
\hline No & 73,458 & 65.3 & 3109 & 48.9 & 50,378 & 64.3 & 1251 & 29.2 & $19.7(40.3)$ \\
\hline Yes & 39,023 & 34.7 & 961 & 29.1 & 27,938 & 35.7 & 375 & 19.3 & $9.8(33.7)$ \\
\hline \multicolumn{10}{|c|}{ Breast feeding } \\
\hline Yes & 106,279 & 94.5 & 2161 & 25.6 & 73,190 & 93.5 & 901 & 16.6 & $9.0(35.2)$ \\
\hline No & 6202 & 5.5 & 1909 & 316.4 & 5126 & 6.5 & 725 & 149.7 & $166.7(52.7)$ \\
\hline \multicolumn{10}{|c|}{ Size of baby at birth } \\
\hline Average/Larger & 95,586 & 85.0 & 3032 & 37.3 & 68,476 & 87.4 & 1214 & 21.4 & $15.9(42.6)$ \\
\hline Small/Very Small & 16,895 & 15.0 & 1038 & 68.8 & 9840 & 12.6 & 412 & 55.6 & $13.2(19.2)$ \\
\hline Total (N) & 112,481 & 100.0 & 4070 & 42.0 & 78,316 & 100.0 & 1626 & 25.6 & $16.4(39.0)$ \\
\hline
\end{tabular}


live births) was among the children belonging to mothers who never breastfed. Mothers who took ANC during pregnancy were observed with 58\% lower U5MR compared to those who did not take full ANC. Similarly mothers who did not take maternal TT immunization reported (33.5 Under-five deaths per 1000 live births) followed by who took maternal TT immunization. Mothers with caesarian delivery reported a $46 \%$ lower under-five mortality rate as compared to normal delivery. We found $42.9 \%$ absolute decline in under-five mortality in those family whose size of the family is less than or equal to five. Similarly, we observed $43.6 \%$ absolute decline in U5MR among those children whose mother's educational status was higher followed by other educational category. An absolute difference of $43.8 \%$ lower U5MR was observed in female children as compared to male children. On comparison of wealth index, we observed U5MR 13.5/1000 live births in poor/poorer category of respondents. Mothers who delivered more than 4 children during her reproductive age group reported absolute difference of U5MR 19.6/1000 live births as compared to mothers who had less than 4 children 13.0/1000 U5MR.

We performed univariate and multivariate survival i.e., Cox proportional hazard model analysis to examine association with socio-economic, demographic, environmental and health related factors with under-five mortality separately for EAG and Non-EAG states. Unadjusted and adjusted hazard ratios (HR) with 95\% confidence interval (CI) for under-five mortality by socio-economic, demographic, environmental and health related factor to EAG and Non-EAG states is depicted in Table 3.

In univariate cox proportional hazard model analysis, we have examined the association of each of socio-economic, demographic, environmental and health predictor variables with under-five mortality for EAG and Non-EAG states separately. The result presents as hazard (relative risk) ratio of under-five mortality for particular category of factor in respect to base-line (reference category) of that factor. The socio-economic variables i.e., mother's education level, family size, wealth quantile, demographic factors i.e., total number children ever born, birth order, environmental factors i.e., sanitation facility, cooking fuel facility and health related factors i.e., maternal TT immunization, place of delivery, antenatal care, breast feeding and size of the baby at the time of birth factors have statistically significant association with under-five mortality in both EAG and Non-EAG states. In addition to the above factors, mother's age at the time of first delivery, sex of child, place of residence and place of delivery were found be significantly associated with under-five mortality in EAG states compared with only post-natal care in Non-EAG states. The mother's age at first delivery and religion were not found to be significantly associated with under-five mortality.

The univariate analysis does not explain clearly the association with under-five mortality for various sub-groups of population because it does not control for other predictor variables when explaining the effect of a particular variable. As mentioned in the methods section, multivariate survival cox proportional 
Table 3. Estimated unadjusted Hazard Ratio (UHR) and adjusted Hazard Ratio (AHR) of under-five death risk by background characteristics in EAG and Non-EAG states of India, 2015-16.

\begin{tabular}{|c|c|c|c|c|c|c|c|c|}
\hline \multirow{2}{*}{$\begin{array}{l}\text { Background } \\
\text { Characteristic }\end{array}$} & \multicolumn{4}{|c|}{ EAG states } & \multicolumn{4}{|c|}{ Non-EAG states } \\
\hline & $\begin{array}{c}\text { UHR } \\
(95 \% \mathrm{CI})\end{array}$ & p-value & $\begin{array}{c}\mathrm{AHR}^{*} \\
(95 \% \mathrm{CI})\end{array}$ & p-value & $\begin{array}{c}\text { UHR } \\
(95 \% \mathrm{CI})\end{array}$ & p-value & $\begin{array}{c}\mathrm{AHR}^{*} \\
(95 \% \mathrm{CI})\end{array}$ & p-value \\
\hline \multicolumn{9}{|c|}{ Mother's age at the time of first delivery } \\
\hline$\leq 15$ & $\begin{array}{c}1.73 \\
(1.15-2.59)\end{array}$ & 0.009 & $\begin{array}{c}1.12 \\
(0.73-1.70)\end{array}$ & 0.611 & $\begin{array}{c}1.42 \\
(0.60-3.32)\end{array}$ & 0.424 & - & - \\
\hline $16-20$ & $\begin{array}{c}1.39 \\
(1.08-1.79)\end{array}$ & 0.010 & $\begin{array}{c}1.21 \\
(0.93-1.58)\end{array}$ & 0.148 & $\begin{array}{c}1.18 \\
(0.80-1.75)\end{array}$ & 0.400 & - & - \\
\hline $21-25$ & $\begin{array}{c}1.25 \\
(0.96-1.62)\end{array}$ & 0.094 & $\begin{array}{c}1.23 \\
(0.94-1.60)\end{array}$ & 0.124 & $\begin{array}{c}0.99 \\
(0.66-1.48)\end{array}$ & 0.955 & - & - \\
\hline $25+{ }^{\otimes}$ & 1.00 & & & & 1.00 & & & \\
\hline \multicolumn{9}{|c|}{ Total no of children ever born (CEB) } \\
\hline$\leq 2^{\otimes}$ & 1.00 & & 1.00 & & 1.00 & & 1.00 & \\
\hline $3-4$ & $\begin{array}{c}1.68 \\
(1.46-1.94)\end{array}$ & 0.000 & $\begin{array}{c}1.58 \\
(1.30-1.92)\end{array}$ & $<0.001$ & $\begin{array}{c}1.62 \\
(1.21-2.16)\end{array}$ & 0.001 & $\begin{array}{c}1.32 \\
(0.97-1.81)\end{array}$ & 0.080 \\
\hline$>4$ & $\begin{array}{c}2.79 \\
(2.38-3.26)\end{array}$ & 0.000 & $\begin{array}{c}2.47 \\
(1.84-3.31)\end{array}$ & $<0.001$ & $\begin{array}{c}2.97 \\
(1.82-4.85)\end{array}$ & 0.000 & $\begin{array}{c}2.46 \\
(1.34-4.52)\end{array}$ & $<0.001$ \\
\hline \multicolumn{9}{|c|}{ Birth order } \\
\hline First $^{\oplus}$ & 1.00 & & 1.00 & & 1.00 & & & \\
\hline Second/third & $\begin{array}{c}1.15 \\
(0.97-1.36)\end{array}$ & 0.099 & $\begin{array}{c}1.16 \\
(0.94-1.42)\end{array}$ & 0.176 & $\begin{array}{c}1.05 \\
(0.77-1.42)\end{array}$ & 0.765 & - & - \\
\hline$\geq$ Fourth & $\begin{array}{c}2.35 \\
(1.98-2.78)\end{array}$ & 0.000 & $\begin{array}{c}2.00 \\
(1.46-2.74)\end{array}$ & $<0.001$ & $\begin{array}{c}2.45 \\
(1.69-3.57)\end{array}$ & 0.000 & - & - \\
\hline \multicolumn{9}{|c|}{ Sex of child } \\
\hline Male $^{\circledast}$ & 1.00 & & 1.00 & & 1.00 & & & \\
\hline Female & $\begin{array}{c}1.37 \\
(1.21-1.55)\end{array}$ & 0.000 & $\begin{array}{c}1.32 \\
(1.16-1.49)\end{array}$ & $<0.001$ & $\begin{array}{c}1.14 \\
(0.87-1.48)\end{array}$ & 0.342 & - & - \\
\hline \multicolumn{9}{|c|}{ Mother' education level } \\
\hline No education & $\begin{array}{c}3.15 \\
(2.27-4.35)\end{array}$ & 0.000 & $\begin{array}{c}1.36 \\
(0.93-1.98)\end{array}$ & 0.109 & $\begin{array}{c}4.74 \\
(2.56-8.78)\end{array}$ & 0.000 & $\begin{array}{c}2.86 \\
(1.39-5.91)\end{array}$ & $<0.001$ \\
\hline Primary & $\begin{array}{c}2.08 \\
(1.47-2.96)\end{array}$ & 0.000 & $\begin{array}{c}1.10 \\
(0.75-1.63)\end{array}$ & 0.614 & $\begin{array}{c}4.06 \\
(2.13-7.73)\end{array}$ & 0.000 & $\begin{array}{c}2.87 \\
(1.40-5.90)\end{array}$ & $<0.001$ \\
\hline Secondary & $\begin{array}{c}1.56 \\
(1.11-2.18)\end{array}$ & 0.009 & $\begin{array}{c}1.03 \\
(0.72-1.48)\end{array}$ & 0.864 & $\begin{array}{c}2.31 \\
(1.28-4.18)\end{array}$ & 0.006 & $\begin{array}{c}2.05 \\
(1.09-3.84)\end{array}$ & 0.030 \\
\hline Higher $^{\oplus}$ & 1.00 & & 1.00 & & 1.00 & & 1.00 & \\
\hline \multicolumn{9}{|c|}{ Family size } \\
\hline$\leq 5$ & $\begin{array}{c}1.80 \\
(1.59-2.03)\end{array}$ & 0.000 & $\begin{array}{c}2.67 \\
(2.30-3.09)\end{array}$ & $<0.001$ & $\begin{array}{c}1.63 \\
(1.24-2.14)\end{array}$ & 0.000 & $\begin{array}{c}1.86 \\
(1.39-2.50)\end{array}$ & $<0.001$ \\
\hline$>5^{\oplus}$ & 1.00 & & 1.00 & & 1.00 & & 1.00 & \\
\hline
\end{tabular}




\section{Continued}

\begin{tabular}{|c|c|c|c|c|c|c|c|c|}
\hline \multicolumn{9}{|c|}{ Wealth Index } \\
\hline Poor/poorer & $\begin{array}{c}2.28 \\
(1.90-2.73)\end{array}$ & 0.000 & $\begin{array}{c}1.01 \\
(0.77-1.35)\end{array}$ & 0.919 & $\begin{array}{c}2.19 \\
(1.60-3.00)\end{array}$ & 0.000 & $\begin{array}{c}1.43 \\
(0.77-2.65)\end{array}$ & 0.260 \\
\hline Middle & $\begin{array}{c}1.63 \\
(1.30-2.06)\end{array}$ & 0.000 & $\begin{array}{c}1.12 \\
(0.86-1.47)\end{array}$ & 0.397 & $\begin{array}{c}1.85 \\
(1.32-2.58)\end{array}$ & 0.000 & $\begin{array}{c}1.47 \\
(0.94-2.29)\end{array}$ & 0.090 \\
\hline Rich/Richer ${ }^{\circledast}$ & 1.00 & & 1.00 & & 1.00 & & 1.00 & \\
\hline \multicolumn{9}{|c|}{ Place of Residence } \\
\hline Urban $^{\circledast}$ & 1.00 & & 1.00 & & 1.00 & & & \\
\hline Rural & $\begin{array}{c}1.55 \\
(1.30-1.85)\end{array}$ & 0.000 & $\begin{array}{c}1.15 \\
(0.94-1.39)\end{array}$ & 0.172 & $\begin{array}{c}1.30 \\
(0.97-1.74)\end{array}$ & 0.079 & - & - \\
\hline \multicolumn{9}{|c|}{ Religion } \\
\hline $\mathrm{Hindu}^{\oplus}$ & 1.00 & & & & 1.00 & & & \\
\hline Muslim & $\begin{array}{c}1.00 \\
(0.85-1.19)\end{array}$ & 0.985 & - & - & $\begin{array}{c}1.06 \\
(0.72-1.56)\end{array}$ & 0.773 & - & - \\
\hline Others & $\begin{array}{c}1.12 \\
(0.77-1.63)\end{array}$ & 0.552 & - & - & $\begin{array}{c}1.39 \\
(0.96-2.00)\end{array}$ & 0.080 & - & - \\
\hline \multicolumn{9}{|c|}{ Access of Sanitation facility } \\
\hline Improved access & $\begin{array}{c}0.63 \\
(0.55-0.72)\end{array}$ & 0.040 & $\begin{array}{c}0.89 \\
(0.75-1.06)\end{array}$ & 0.184 & $\begin{array}{c}0.63 \\
(0.48-0.82)\end{array}$ & 0.001 & $\begin{array}{c}0.86 \\
(0.60-1.23)\end{array}$ & 0.420 \\
\hline Unimproved access $^{\circledast}$ & 1.00 & & 1.00 & & 1.00 & & 1.00 & \\
\hline \multicolumn{9}{|c|}{ Type of cooking fuel } \\
\hline Solid fuel & $\begin{array}{c}1.65 \\
(1.38-1.97)\end{array}$ & 0.000 & $\begin{array}{c}1.07 \\
(0.85-1.35)\end{array}$ & 0.548 & $\begin{array}{c}1.32 \\
(1.01-1.73)\end{array}$ & 0.041 & $\begin{array}{c}0.82 \\
(0.54-1.24)\end{array}$ & 0.340 \\
\hline Clean Fuel $^{\circledast}$ & 1.00 & & 1.00 & & 1.00 & & 1.00 & \\
\hline \multicolumn{9}{|c|}{ Maternal TT immunization } \\
\hline No & $\begin{array}{c}1.95 \\
(1.64-2.33)\end{array}$ & 0.000 & $\begin{array}{c}1.33 \\
(1.10-1.60)\end{array}$ & 0.003 & $\begin{array}{c}1.93 \\
(1.37-2.73)\end{array}$ & 0.000 & $\begin{array}{c}1.33 \\
(0.94-1.90)\end{array}$ & 0.110 \\
\hline $\mathrm{Yes}^{\circledast}$ & 1.00 & & 1.00 & & 1.00 & & 1.00 & \\
\hline \multicolumn{9}{|c|}{ Place of Delivery } \\
\hline Home & $\begin{array}{c}1.87 \\
(1.54-2.26)\end{array}$ & 0.000 & $\begin{array}{c}1.03 \\
(0.81-1.31)\end{array}$ & 0.800 & $\begin{array}{c}2.10 \\
(1.42-3.10)\end{array}$ & 0.000 & $\begin{array}{c}1.05 \\
(0.68-1.63)\end{array}$ & 0.830 \\
\hline Public & $\begin{array}{c}1.16 \\
(0.97-1.40)\end{array}$ & 0.110 & $\begin{array}{c}0.88 \\
(0.71-1.09)\end{array}$ & 0.229 & $\begin{array}{c}1.34 \\
(0.99-1.81)\end{array}$ & 0.060 & $\begin{array}{c}1.05 \\
(0.78-1.43)\end{array}$ & 0.730 \\
\hline Private $^{\circledast}$ & 1.00 & & 1.00 & & 1.00 & & 1.00 & \\
\hline \multicolumn{9}{|c|}{ Type of Delivery } \\
\hline Normal & $\begin{array}{c}1.50 \\
(1.18-1.90)\end{array}$ & 0.001 & $\begin{array}{c}0.96 \\
(0.73-1.27)\end{array}$ & 0.780 & $\begin{array}{c}1.25 \\
(0.91-1.71)\end{array}$ & 0.166 & - & - \\
\hline Caesarian $^{\otimes}$ & 1.00 & & 1.00 & & 1.00 & & & \\
\hline
\end{tabular}




\begin{tabular}{|c|c|c|c|c|c|c|c|c|}
\hline \multicolumn{9}{|c|}{ Antenatal Care } \\
\hline No & $\begin{array}{c}1.62 \\
(1.42-1.85)\end{array}$ & 0.000 & $\begin{array}{c}1.05 \\
(0.91-1.22)\end{array}$ & 0.490 & $\begin{array}{c}1.93 \\
(1.36-2.75)\end{array}$ & 0.000 & $\begin{array}{c}1.12 \\
(0.77-163)\end{array}$ & 0.540 \\
\hline Yes $^{\circledast}$ & 1.00 & & 1.00 & & 1.00 & & 1.00 & \\
\hline \multicolumn{9}{|c|}{ Postnatal Care } \\
\hline No & $\begin{array}{c}1.11 \\
(0.97-1.26)\end{array}$ & 0.127 & - & - & $\begin{array}{c}1.39 \\
(1.05-1.84)\end{array}$ & 0.021 & $\begin{array}{c}1.29 \\
(0.98-1.71)\end{array}$ & 0.070 \\
\hline Yes $^{\oplus}$ & 1.00 & & & & 1.00 & & 1.00 & \\
\hline \multicolumn{9}{|c|}{ Breast feeding } \\
\hline Yes & $\begin{array}{c}0.29 \\
(0.24-0.34)\end{array}$ & 0.000 & $\begin{array}{c}0.31 \\
(0.26-0.37)\end{array}$ & $<0.001$ & $\begin{array}{c}0.22 \\
(0.16-0.30)\end{array}$ & 0.000 & $\begin{array}{c}0.24 \\
(0.17-0.34)\end{array}$ & $<0.001$ \\
\hline $\mathrm{No}^{\circledast}$ & 1.00 & & 1.00 & & 1.00 & & 1.00 & \\
\hline \multicolumn{9}{|c|}{ Size of baby at birth } \\
\hline Average/large ${ }^{\circledast}$ & 1.00 & & 1.00 & & 1.00 & & 1.00 & \\
\hline $\begin{array}{c}\text { Small/Very } \\
\text { Small }\end{array}$ & $\begin{array}{c}1.66 \\
(1.43-1.93)\end{array}$ & 0.000 & $\begin{array}{c}1.48 \\
(1.27-1.72)\end{array}$ & $<0.001$ & $\begin{array}{c}2.59 \\
(1.86-3.60)\end{array}$ & 0.000 & $\begin{array}{c}2.28 \\
(1.63-3.20)\end{array}$ & $<0.001$ \\
\hline
\end{tabular}

*Adjusted Model include those factors were found statistically significant (p value $<0.05$ ) in unadjusted model (UHR). @ Reference group.

hazard models were considered to examine the association of factors with under-five mortality. We have dropped those variables which were not found statistically significant in univariate analysis in multivariate analysis for both EAG and Non-EAG states. We found higher hazard of under-five mortality among mothers who had more than four births in EAG states (AHR $=2.47,95 \%$ CI: $1.84-3.31)$ and Non-EAG (AHR $=2.46,95 \%$ CI: $1.34-4.52)$ states as compared to mothers who have only $\leq 2$ births after controlling for other factors in the study. Higher order births were found statistically significant to higher risk of under-five mortality (AHR $=2.00,95 \% \mathrm{CI}$ : $1.46-2.74$ ) in EAG states controlling for other factors. In both groups of states, mother's education was found to be significantly associated with under-five mortality. Illiterate mothers had twice risk of under-five mortality as compared to higher educated mothers in only Non-EAG states. Size of family with less than six members was found to be at higher risk of under-five mortality in EAG states (AHR $=2.67,95 \%$ CI: 2.30 3.09), Non EAG states (AHR = 1.86, 95\% CI: $1.39-2.50$ ). In EAG states female children experienced higher U5MR as compared to male children (AHR $=1.32$, 95\% CI: 1.16 - 1.49). Those mothers who had not been fully TT immunized during pregnancy reported increased risk of under-five mortality in only EAG states (AHR $=1.33$, 95\% CI: 1.10 - 1.60). Those mothers who breastfed their under-five children were found with $69 \%$ lower hazard of under-five mortality in EAG states and 76\% lower hazard in Non-EAG states. Children born with small/ very small size at birth were found to be at higher hazards of under-five mortali- 
ty in EAG states $(\mathrm{AHR}=1.48,95 \% \mathrm{CI}: 1.27-1.72)$ and Non EAG states $(\mathrm{AHR}=$ $2.2895 \%$ CI: 1.63 - 3.20) compared to average/large size of the baby at the time of birth after controlling for other factors. The under-five hazard ratio is three times higher among children who were not breastfed in EAG states, and fourtimes higher in non-EAG states compared those children who were breastfed controlling for other factors.

\section{Discussion}

This study was done to examine the factors associated with under-five mortality in EAG and Non-EAG states of India. The most significant variables found were total number of births, birth order, mother's education, family size, breast feeding and size of baby at the time of birth. "The complex setting and the interaction of socio-economic, biological and demographic factors in developing countries often act as detriments to maternal, infant and child survival in the population" [10]. It is evident in univariate analysis that in mother's with age below 15 years and $16-21$ years at the time of delivery, childbirth can pose greater risk of complications. The children born to mothers in these groups are at a higher risk of under-five mortality in EAG states. Other studies also found higher risk of under-five deaths in younger mothers [11] [12] [13]. Mother's education seems to have a direct effect on how the child is cared for. Educated mothers are better able to ensure a hygienic environment, nutritious food, and health care facilities for their children. Taking into account the education level of mothers, it was seen in EAG states, $37.3 \%$ mothers who were illiterate lost their child before they reached five years of age as compared to $16.8 \%$ mothers in Non-EAG states. Similar findings also reported mother's education to be associated with a reduction of under-five mortality [14] [15]. We found higher number of births to be associated with more risk of under-five mortality. Studies also showed similar results among children whose mothers had more births to have more risk of under-five mortality [16] [17]. Higher birth order is also related with low knowledge of family planning and contraceptives. A family size of less than five members was also found to have significantly higher hazards of under-five mortality. Consistent findings in other studies reported larger family size to be associated with a lower risk of under-five mortality [18] [19] [20]. The strong preference for male child in India makes the family more cautious with prompt action towards the health of male child, leading to higher post-neonatal and U5MR in female children. More variation is apparent between EAG and Non-EAG states when the sex of deceased child is taken into account. Few studies also reported similar findings [21] [22]. Urban population has comparatively easy availability and accessibility of quality medical services, along with more knowledge about seeking help when required than the rural ones. The respondents with under-five mortality were majorly from rural setting in both EAG and Non-EAG states. Along with the social circumstances, economic conditions also influence the health status; in terms of calorie and nutrition consumption, and also the use of medical facilities. Under-five mortality is lower among children whose moth- 
ers received ANC check-ups as compared to those children born to mothers who either did not receive any ANC check-up or received less than they actually should. ANC services are correlated with receipt of tetanus toxoid (TT) injections, consumption of IFA tablets or syrups and other supplements besides regular monitoring of weight and blood pressure and growth examination. A stark difference is visible in the number of ANC visits made by the mother between the EAG and Non-EAG states [23] [24]. Health care institutions provide better sanitary conditions and there is availability of the essential healthcare assistance. Hence, there is lower U5MR in institutional deliveries than in home deliveries. Under-five mortality among babies of small and very small sizes at birth is almost three/four times as high than among babies whose size at birth is average [25] [26] [27].

\section{Conclusion}

We conclude that this study has been done for the reduction of under-five mortality and adoption of comprehensive strategies for EAG and Non EAG states of India. Although a continuum of healthcare during pregnancy, childbirth, and even during the under-five period is necessary for further reductions in under-five mortality, ensuring uptake of antenatal checkup during pregnancy, an adequate quantity of TT injections during pregnancy should be a priority in maternal and child health related programmatic interventions and strategies. Our findings indicate that children born to young mothers experienced higher mortality so there is a need to enhance reproductive knowledge and family planning. Targeting groups such as mother's age $<20$ years at first birth and birth order of more than 2, in order to provide the continuum of essential maternal and childcare would be a crucial step if under-five mortality in EAG and Non EAG states of India is to be further reduced. In addition, improving the overall household environment by increasing access to improved toilets and fuel can also contribute to further reductions in under-five mortality in EAG states of India.

\section{Ethical Consideration}

The secondary data set is used available in public domain for this study so there is no need of any ethical consideration.

\section{Funding}

This research is work of my $\mathrm{PhD}$ thesis and our university has no provision of any specific grant from publication.

\section{Conflicts of Interest}

The authors have no conflict of interest to declare.

\section{References}

[1] The United Nations Inter-Agency Group for Child Mortality Estimation (2019) Le- 
vels \& Trends in Child Mortality: 2019 Report. https://www.unicef.org/media/60561/file/UN-IGME-child-mortality-report-2019.pdf

[2] Yojna, J.S. (2005) National Health Mission, Ministry of Health and Family Welfare. https://nhm.gov.in/WriteReadData/1892s/97827133331523438951.pdf

[3] Kumar, C., Singh, P.K and Rai, R.K. (2012) Under-Five Mortality in High Focus States in India: A District Level Geospatial Analysis. PLoS ONE, 7, e37515. https://doi.org/10.1371/journal.pone.0037515

[4] Bora, J.K. and Saikia, N. (2018) Neonatal and Under-Five Mortality Rate in Indian Districts with Reference to Sustainable Development Goal 3: An Analysis of the National Family Health Survey of India (NFHS), 2015-2016. PLoS ONE, 13, e0201125. https://doi.org/10.1371/journal.pone.0201125

[5] (2011) Annual Report: 2010-11. Ministry of Health and Family Welfare, 1-2. https://main.mohfw.gov.in/sites/default/files/26697288736.pdf

[6] India, P. (2011) Census of India 2011 Provisional Population Totals. http://censusindia.gov.in/2011-prov-results/prov results paper1 india.html

[7] United Nations (2016) Goal 3: Ensure Healthy Lives and Promote Well-Being for All at All Ages. http://www.un.org/sustainabledevelopment/health

[8] International Institute for Population Sciences (2017) National Family Health Survey (NFHS-4) (2015-16). http://rchiips.org/NFHS/NFHS-4Reports/India.pdf

[9] Mosley, W.H. and Chen, L.C. (1984) An Analytical Framework for the Study of Child Survival in Developing Countries. Population and Development Review, 10, 25-45. https://doi.org/10.2307/2807954

[10] Govindasamy, P. (1997) Maternal Education and the Utilization of Maternal and Child Health Services in India. Maternal Education and the Utilization of Maternal and Child Health Services in India, 5, 1-28.

https://citeseerx.ist.psu.edu/viewdoc/download?doi=10.1.1.492.7189\&rep=rep1\&typ $\underline{\mathrm{e}=\mathrm{pdf}}$

[11] Mani, K. (2012) Determinants of Under-Five Mortality in Rural Empowered Action Group States in India: An Application of Cox Frailty Model. International Journal of $M C H$ and AIDS, 1, 60-72.

[12] Abir, T., Agho, K.E., Page, A.N., Milton, A.H. and Dibley, M.J. (2015) Risk Factors for Under-5 Mortality: Evidence from Bangladesh Demographic and Health Survey, 2004-2011. BMJ Open, 5, e006722. https://doi.org/10.1136/bmjopen-2014-006722

[13] Singh, R. and Tripathi, V. (2015) Under-Five Mortality among Mothers Employed in Agriculture: Findings from a Nationally Representative Sample. PeerJ, 3, e710. https://doi.org/10.7717/peerj.710

[14] Hossain, M.M., Mani, K.K.C. and Islam, M.R. (2015) Prevalence and Determinants of the Gender Differentials Risk Factors of Child Deaths in Bangladesh: Evidence from the Bangladesh Demographic and Health Survey, 2011. PLoS Neglected Tropical Diseases, 9, e0003616. https://doi.org/10.1371/journal.pntd.0003616

[15] Ezeh, O.K., Agho, K.E., Dibley, M.J., Hall, J.J. and Page, A.N. (2015) Risk Factors for Postneonatal, Infant, Child and Under-5 Mortality in Nigeria: A Pooled Cross-Sectional Analysis. BMJ Open, 5, e006779.

https://doi.org/10.1136/bmjopen-2014-006779

[16] Singh, R. and Tripathi, V. (2013) Maternal Factors Contributing to Under-Five Mortality at Birth Order 1 to 5 in India: A Comprehensive Multivariate Study. SpringerPlus, 2, Article No. 284. https://doi.org/10.1186/2193-1801-2-284 
[17] Zanini, R.R., Moraes, A.B., Giugliani, E.R.J. and Riboldi, J. (2011) Determinantescontextuais da mortalidade neonatal no Rio Grande do Sulpordoismodelos de análise. Revista de SaúdePública, 45, 79-89.

https://doi.org/10.1590/s0034-89102011000100009

[18] Pandey, M.K. (2009) ASARC Working Paper 2009/12: Maternal Health and Child Mortality in Rural India.

https://crawford.anu.edu.au/acde/asarc/pdf/papers/2009/WP2009 12.pdf

[19] Uddin, M.J. and Hossain, M.Z. (2010) Predictors of Infant Mortality in a Developing Country. Asian Journal of Epidemiology, 3, 84-99.

https://doi.org/10.3923/aje.2010.84.99

[20] Kaldewei, C. (2010) Determinants of Infant and Under-Five Mortality-The Case of Jordan (Technical Note, February 2010).

https://www.un.org/en/development/desa/policy/capacity/country documents/jord an desa mdg4 technote mar2010.pdf

[21] Alonso, V., Fuster, V. and Luna, F. (2005) Causes of Neonatal Mortality in Spain (1975-98): Influence of Sex, Rural-Urban Residence and Age at Death. Journal of Biosocial Science, 38, 537-551. https://doi.org/10.1017/s0021932005026957

[22] Perianayagam, A. and Abhishek, G. (2008) Neonatal Mortality in the Empowered Action Group States of India: Trends and Determinants. Journal of Biosocial Science, 40, 183-201. https://doi.org/10.1017/s0021932007002623

[23] Blencowe, H., Lawn, J., Vandelaer, J., Roper, M. and Cousens, S. (2010) Tetanus Toxoid Immunization to Reduce Mortality from Neonatal Tetanus. International Journal of Epidemiology, 39, i102-i109. https://doi.org/10.1093/ije/dyq027

[24] Chowdhury, A.H. (2013) Determinants of Under-Five Mortality in Bangladesh. Open Journal of Statistics, 3, 213-219. https://doi.org/10.4236/ojs.2013.33024

[25] Adhikari, R. and Podhisita, C. (2010) Household Headship and Child Death: Evidence from Nepal. BMC International Health and Human Rights, 10, Article No. 13. https://doi.org/10.1186/1472-698x-10-13

[26] Nasejje, J.B., Mwambi, H.G. and Achia, T.N.O. (2015) Understanding the Determinants of Under-Five Child Mortality in Uganda Including the Estimation of Unobserved Household and Community Effects Using Both Frequentist and Bayesian Survival Analysis Approaches. BMC Public Health, 15, Article No. 1003. https://doi.org/10.1186/s12889-015-2332-y

[27] Dejene, T. and Girma, E. (2013) Social Determinants of Under-Five Mortality in Ethiopia: Event History Analysis Using Evidence from Ethiopian Demographic and Health Survey (EDHS). Health, 5, 879-884.

https://doi.org/10.4236/health.2013.55115 